\title{
Coarctation of the aorta
}

\author{
J A M E S D. WISHEAR T ${ }^{1}$ \\ Royal Victoria Hospital, Belfast
}

In a series of 70 patients who had surgical correction of coarctation of the aorta between 1952 and 1969 , the operative mortality was $7 \%$ and the complication rate was $14 \%$. The mortality was particularly high in adult males over 30, with pre-operative evidence of left ventricular ischaemia. Simple surgical procedures had satisfactory results, but the use of prostheses carried a high risk, and turning down the left subclavian artery failed to lower the blood pressure. The blood pressure score fell by $68 \%$ after operation, and by a further $8 \%$ following discharge from hospital. This result was maintained up to 17 years after operation, and may be expected in all groups of patients.

Coarctation of the aorta has been surgically treated with success since 1945 (Crafoord and Nylin, 1945 ; Gross and Hufnagel, 1945). As varying techniques and results are reported from different centres it was considered timely to review the experience at this centre with 70 patients, spanning 17 years. The results have been analysed with regard to the rate of post-operative mortality and complications, the effect of specific operative procedures and the lowering of systolic blood pressure immediately following, and up to 17 years after surgery.

\section{CLINICAL MATERIAL}

These 70 patients include males and females of all age groups (Fig. 1 ; Table 1 , whose clinical findings differed in no way from those usually described in this condition. There were associated cardiovascular

1Present address: National Heart Hospital, Westmoreland Street, London, W.1

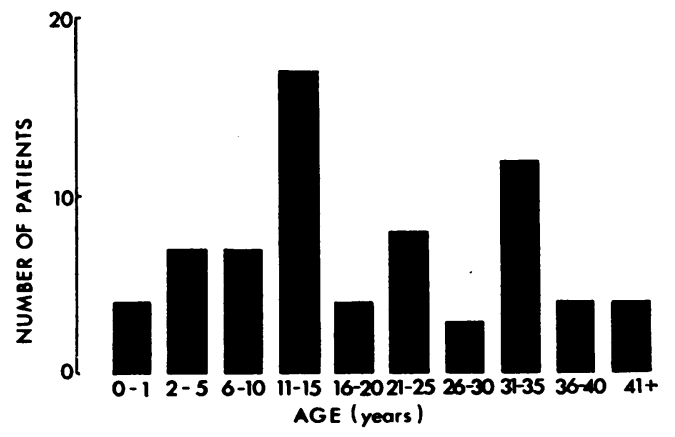

FIG. 1. Age distribution. anomalies in $23 \%$ of the total series (17 patients), the most common being patent ductus arteriosus (Table II).

T A B L E I

SEX DISTRIBUTION

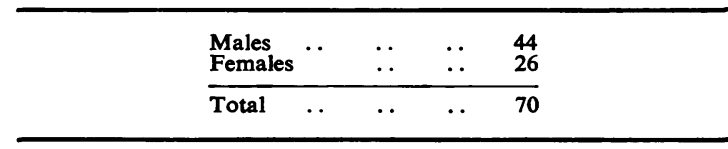

T A B L E I I

ASSOCIATED CARDIOVASCULAR ANOMALIES

\begin{tabular}{|c|c|c|c|}
\hline & & No. of Patients & $\%$ \\
\hline $\begin{array}{l}\text { P.D.A. ... } \\
\text { Aortic incompetence } \\
\text { Aortic stenosis } \\
\text { Atrial septal defect }\end{array}$ & $\ddot{.}$ & $\begin{array}{r}11 \\
3 \\
2 \\
1\end{array}$ & $\begin{array}{r}16 \\
4 \\
2 \\
1\end{array}$ \\
\hline Total & .. & 17 & 23 \\
\hline
\end{tabular}

BLOOD PRESSURE In each case the blood pressure, measured in the right arm (Rathi and Keith, 1964), was corrected for normal age and sex variations on the basis of data contained in population tables for subjects over 10 years (Hamilton, Pickering, Roberts, and Sowry, 1954). The extent to which blood pressure was elevated above normal is recorded in arbitrary units as a 'score'.

Analysis of the pre-operative scores with regard to age and sex showed that males had a higher elevation of blood pressure than females and that the rise was maximal in the 26-30 age group (Table III, Fig. 2).

T A B L E I I I

PRE-OPERATIVE MEAN BLOOD PRESSURE SCORE

\begin{tabular}{|c|c|c|c|c|c|c|}
\hline & & & & Males & Females & All \\
\hline $\begin{array}{l}\text { No. of patients } \\
\text { Mean score }\end{array}$ & $\ldots$ & $\begin{array}{l}\cdots \\
\cdots\end{array}$ & 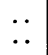 & $\begin{array}{r}26 \\
153\end{array}$ & $\begin{array}{l}21 \\
86\end{array}$ & $\begin{array}{r}47 \\
123\end{array}$ \\
\hline
\end{tabular}




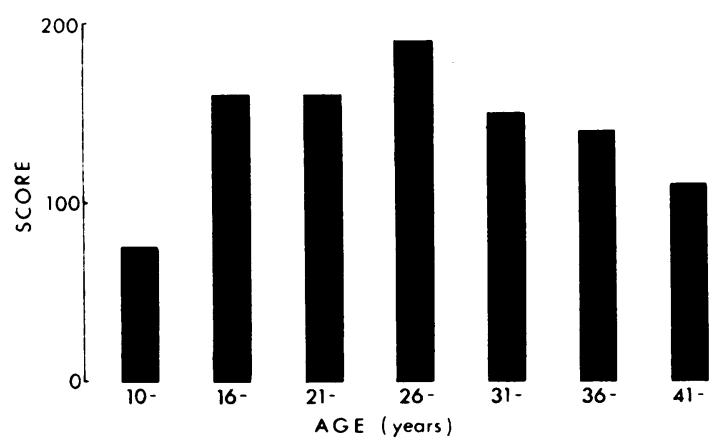

FIG. 2. Pre-operative mean systolic blood pressure score.

CHEST RADIOGRAPH Postero-anterior chest films were available for inspection in 61 cases, and, of these, two were within normal limits. The most common abnormal features in the remaining 59 were ribnotching, increase in size of the left ventricle, and abnormalities of the aortic knuckle (Table IV).

\section{T A B L E I V}

RADIOLOGICAL ABNORMALITIES

\begin{tabular}{|c|c|c|}
\hline & No. of Patients & $\%$ \\
\hline \multirow{2}{*}{$\begin{array}{l}\text { Rib notching } \\
\text { L.V. enlargement } \\
\text { Abnormal aortic knuckle } \\
\text { Cardiomegaly } \\
\text { Displacement of aortic } \\
\text { arch to right }\end{array}$} & $\begin{array}{r}39 \\
36 \\
26 \\
4\end{array}$ & $\begin{array}{r}67 \\
60 \\
44 \\
7\end{array}$ \\
\hline & 4 & 7 \\
\hline
\end{tabular}

ELECTROCARDIOGRAM Electrocardiographic examination was carried out in 62 cases, including all but five of the 53 patients with pure coarctation over 10 years. In this group (Table V) there was no abnormality in 23 cases, and, in the remaining 25 , left ventricular hypertrophy and left ventricular ischaemia were the most common findings.

\section{T A B L E V}

ELECTROCARDIOGRAPHIC ABNORMALITIES

\begin{tabular}{ll|c|c}
\hline & & No. of Patients & $\%$ \\
\hline L.V. hypertrophy & $\ldots$ & 24 & 50 \\
L.V. ischaemia $\ldots$ & $\ldots$ & 11 & 22 \\
Left axis deviation & $\ldots$ & 9 & 18 \\
Right bundle-branch & & & \\
block . . & $\ldots$ & 4 & 8 \\
R.V. hypertrophy & $\ldots$ & 1 & 2 \\
\hline
\end{tabular}

OPERATIVE PROCEDURES Seventy-one operations were carried out on 70 patients, as shown in Figure 3. In the 11 cases with associated patent ductus arteriosus, the duct was divided and ligated. Where there was a post-stenotic aneurysm, the dilatation was resected with the coarctation in two patients and corrected by a plastic procedure in the third. Two intercostal aneurysms were divided and ligated.

In the latter half of the period under review, hypotensive anaesthesia, using trimetaphan (Frederiksen and Møller, 1964), was employed without complication. Hypothermia was used in two cases when it was considered that the collateral circulation was poor and distal perfusion might be inadequate during the period of aortic occlusion (Owens and Swan, 1963). Left atrial, or femoral vein, to femoral artery bypass techniques (Cooley, DeBakey, and Morris, 1957; Neville, Cox, Leininger, and Pifarré, 1968; Shumacker, King, Nahrwold, and Waldhausen, 1968) have not been employed.

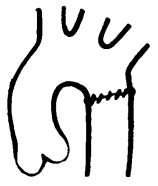

Resection and direct anastomosis

no. 61

cases

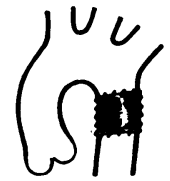

Prosthetic circumferential graft

5

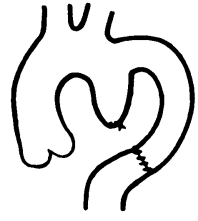

Anastomosis of I. subclavian a. to distal aorta 3

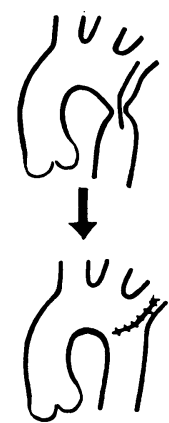

Aortoplasty
+1 negative exploration

FIG. 3. Operative procedures. 


\section{RESULTS OF OPERATION}

\section{MORTALITY}

Early The operative mortality was $7 \%$ and the causes of death may be seen in Table VI. All who died were males, and four, who were aged between 30 and 40 years, had had pre-operative electrocardiographic changes showing left ventricular hypertrophy and ischaemia.

T A B LE V I

CAUSES OF OPERATIVE MORTALITY

\begin{tabular}{|c|c|c|}
\hline & & No. of Patients \\
\hline $\begin{array}{l}\text { Haemorrhage } \\
\text { Respiratory failure ... } \\
\text { Dissecting aneurysm } \\
\text { Coronary thrombosis }\end{array}$ & $\begin{array}{l}\cdots \\
\cdots \\
\cdots\end{array}$ & $\begin{array}{l}2 \\
1 \\
1 \\
1\end{array}$ \\
\hline Total & .. & 5 \\
\hline
\end{tabular}

Fatal haemorrhage occurred in two patients following insertion of a prosthesis. In one there was uncontrollable bleeding through a nylon graft and in the other a leaking anastomosis required re-exploration, but cardiac arrest occurred before blood loss could be stopped and the patient died three days later, having suffered irreversible cerebral damage. The dissecting aneurysm occurred on the 9th postoperative day, and at post-mortem examination medial necrosis of the aorta was found. The coronary thrombosis occurred immediately after operation and necropsy showed the additional presence of an old infarction. A 6 weeks' old infant with associated patent ductus died from respiratory failure.

Late Two further patients died at one and three years respectively after operation.

A boy of 15 years died during open-heart surgery for associated aortic stenosis, one year after resection of the coarctation. A 19-year-old girl, who had originally presented with subarachnoid haemorrhage, suffered recurrent bleeding three years after operation and subsequently died.

COMPLICATIONS OF SURGERY Significant complications of surgery occurred in $10(14 \%)$ patients (Table VII).

T A B L E V I I

POST-OPERATIVE COMPLICATIONS

\begin{tabular}{|c|c|}
\hline & No. of Patients \\
\hline $\begin{array}{l}\text { Haemorrhage } \\
\text { Chylous pleural effusion } \ldots \\
\text { Hoarseness } \ldots \quad \ldots \\
\text { Paraplegia } \ldots \\
\text { Thrombosis of graft } \\
\text { Recurrence of coarctation } \ldots \\
\text { Failure to find coarctation } \ldots\end{array}$ & $\begin{array}{l}2 \\
2 \\
3 \\
11 \\
11 \\
1 \\
1\end{array}$ \\
\hline Total & 10 \\
\hline
\end{tabular}

1 Same patient
Chylous pleural effusion occurred twice, and while one case required re-exploration on the 15th day, in the other it resolved spontaneously. Both are now well.

Hoarseness occurred in three patients, and while all were apparently normal at review, two claimed that their voices had failed to regain their former qualities after five and 12 years respectively.

One unfortunate girl of 13 years, who had a 2-in. $(50.8 \mathrm{~mm}$.) long circumferential Teflon prosthesis inserted to replace the aorta which was involved in coarctation and post-stenotic aneurysm, suffered immediate paraplegia. The aorta had been occluded for 78 minutes. Subsequently her graft thrombosed, so that she now has absent femoral pulsations, proximal hypertension and residual motor disability of the lower limbs.

A boy of 12 years, who had his left subclavian artery anastomosed to the aorta distal to the coarctation, developed narrowing at the origin of the artery. $\mathrm{Re}$-operation was carried out, seven years later, when the narrowing was successfully resected and continuity of the aorta restored by direct anastomosis.

In a male infant of 6 months, thoracotomy was carried out with a view to resection of a coarctation, but the lesion could not be identified. He was subsequently well, but now, some 11 years later, he awaits re-operation for a coarctation which has recently been demonstrated at angiography.

RESULTS OF SPECIFIC OPERATIVE PROCEDURES In five cases circumferential replacement of the aorta was carried out, using prosthetic material. Two patients died as a result of haemorrhage, one has paraplegia and a thrombosed graft, while the remaining two are well.

In three cases the left subclavian artery was anastomosed to the distal aorta. One boy required re-operation, as above, and the other two have residual proximal hypertension of $210 / 110$ and $190 / 75 \mathrm{~mm}$. Hg respectively.

Aortoplasty was successful, and free from complication, in one patient, who also had a poststenotic aneurysm.

Resection and direct anastomosis was carried out in 61 cases with an operative mortality of $5 \%$ and a complication rate of $11 \%$.

EARLY FALL IN BLOOD PRESSURE The effect of surgery on blood pressure has been analysed only in those patients aged 10 years or more who had coarctation free of any associated cardiovascular anomaly.

The records of systolic post-operative blood pressure, measured at the time of discharge from hospital, were available in 39 out of 48 such cases. The mean score had fallen to $32 \%$ of the preoperative level (Table VIII). Figure 4 illustrates 
T A B L E V I I I

EFFECTS OF OPERATION ON MEAN BLOOD PRESSURE SCORE

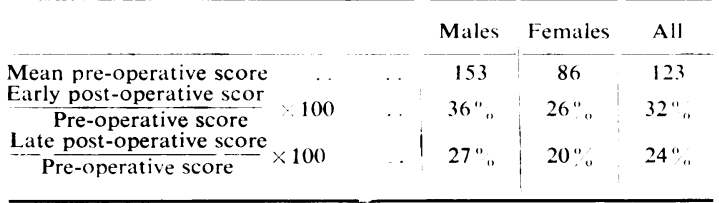

that the higher pre-operative scores achieved a proportionately greater percentage fall, but there is no clear relationship between the fall in score and age.

In terms of individual patients, $38 \%$ had scores of 50 or more at the time of discharge, males outnumbering females by 2 to 1 . A score of 50 is approximately equal to a systolic pressure of $150 \mathrm{~mm} . \mathrm{Hg}$ in a young adult male.

REVIEW

LATE FALL IN BLOOD PRESSURE Of the 70 patients. seven had died, three had emigrated, and eight could not be traced. The remaining 52 were reviewed by the author in January 1969. Forty had had a pure coarctation and, having been aged 10 or more at the time of surgery, were available for long-term assessment of the effect of operation on systolic blood pressure. The mean score had further fallen to $24 \%$ of the pre-operative level (Table VIII).
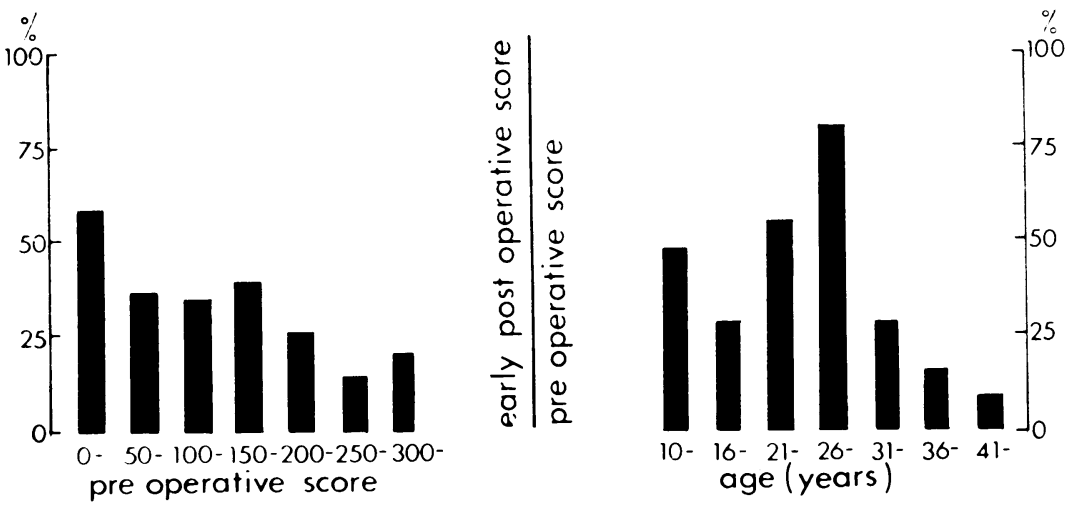

FIG. 4. Early effects of operation on mean systolic blood pressure score related to preoperative score and age.
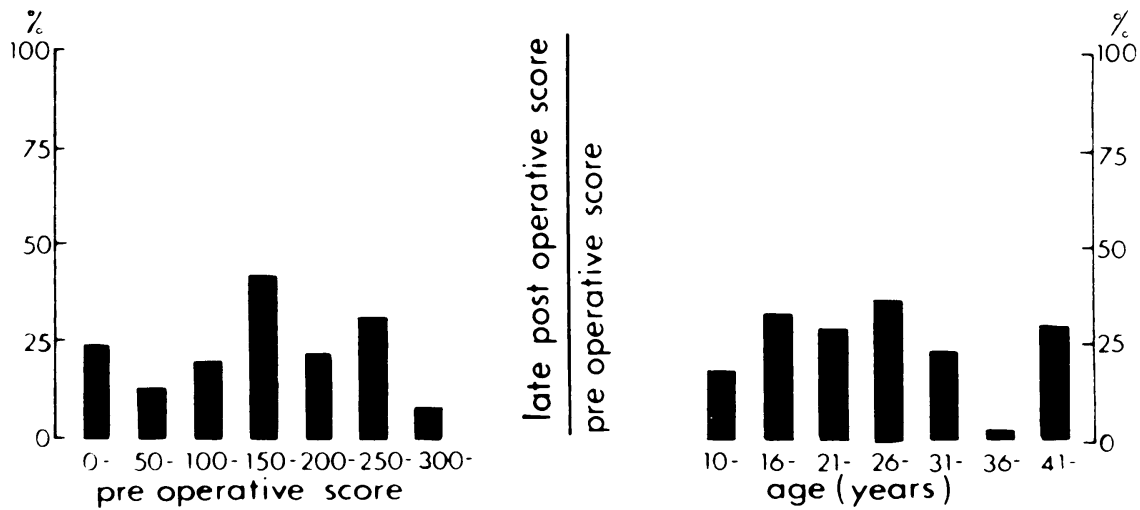

FIG. 5. Late effects of operation on mean sistolic blool pressure score related to preoperative score and age. 
T A B L E IX

FOLLOW-UP

\begin{tabular}{l|cc|c|c|c}
\hline Period of follow-up (years) & $0-3$ & $3-5$ & $5-10$ & $10-17$ \\
\hline $\begin{array}{l}\text { No. of patients } . . \\
\text { Post-operative score }\end{array} \times 100$ &.. & 9 & 15 & 7 & 9 \\
Pre-operative score & & $30 \%$ & $25 \%$ & $1 \%$ & $25 \%$ \\
\hline
\end{tabular}

There is a similar late fall in mean score throughout the whole range of pre-operative scores and in all age groups (Fig. 5).

The findings after different lengths of followup are summarized in Table IX.

In considering individual patients, $20 \%$ at review had a score of 50 or more, there being a slight excess of males.

CHEST RADIOGRAPH Of the patients reviewed, $60 \%$ showed enlargement of the left ventricle both before and after operation.

ELECTROCARDIOGRAM Among those reviewed, a pre-operative electrocardiogram has shown 19 with left ventricular hypertrophy, eight of whom had additional left ventricular ischaemia. Four patients had unchanged electrocardiograms at follow-up, and the remaining $79 \%$ showed normal or improved records.

\section{DISCUSSION}

Abbott (1928) and Reifenstein, Levine, and Gross (1947) showed that 60 to $70 \%$ of patients with coarctation of the aorta died under 40 years of age. Since the first operations were carried out by Crafoord and Nylin (1945) and Gross and Hufnagel (1945), the place of surgery in treating coarctation has been firmly established. Nevertheless, operation carries a significant mortality and morbidity rate in all age groups, more particularly at the extremes of life (Braimbridge and Yen, 1965 ; Brom, 1965 ; Shumacker et al., 1968). It was therefore deemed appropriate to make a detailed analysis of the effeots of surgery since the first operations for coarctation in Belfast were reported by Marshall and Pantridge (1956).

OPERATIVE TECHNIQUE Operative techniques may be classified as follows:

\section{Simple reconstruction}

(1) Resection and end-to-end anastomosis

(2) Aortoplasty with, or without, patch graft

$$
\text { By-pass }
$$

(1) Left subclavian artery

(2) Tubular prosthesis
(1) Homograft

Circumferential graft

(2) Prosthetic replacement

Simple techniques produce a satisfactory result in 85 to $90 \%$ of cases. Resection and end-to-end anastomosis has been the most widely used method, and, where the ends come together easily, it poses only the problem of failure of growth of the anastomosis in young subjects, when a continuous suture has been used (Mortensen, Cutler, Rumel, and Veasy, 1959). Schuster and Gross (1962) sought to overcome this problem by using interrupted everting sutures, though it is now considered that one interruption in the suture line will permit growth (Bull, Hoeksema, Duckworth, and Mustard, 1963). Peiletier, Davignon, F.-Ethier, and Stanley (1969) have recently shown that, providing the anastomosis is at least $55 \%$ of the diameter of the aorta, there is no pressure gradient. Aortoplasty has the advantage of requiring less dissection and poses no growth problem related to surgical techniques (Vossschulte, 1961). Although it is often necessary to use prosthetic patch grafts, this is no disadvantage. Both techniques have had satisfactory results in our hands.

By-passing the constriction by using the left subclavian artery (Blalock and Park, 1944) has not proved to be successful, as the artery, having been turned down, may kink at its origin. This will cause an obstruction to aortic flow which is considered by Shumacker et al. (1968) to prevent blood pressure falling in many cases. We have experienced one case who required re-operation because of such narrowing, and the other two cases have residual proximal hypertension. Other bypass techniques using Dacron tubes (Morris, Cooley, De Bakey, and Crawford, 1960), or excised segments of the left subclavian artery (Shumacker et al., 1968), seem needlessly complex and have been used in only a few centres.

Circumferential replacement was extensively used by Gross, who employed homograft material to replace the excised aorta (Gross, 1953 ; Schuster and Gross, 1962). Although Foster, Collins, Jacobs, and Scott (1965) report excellent results with no sign of narrowing, dilatation or degeneration after five to nine years, Report of the Section on Cardiovascular Surgery (1957) found over 5\% incidence of graft disruption. Gross reports that $50 \%$ of the homografts were calcified after five years (Schuster and Gross, 1962). For these reasons, the use of homografts for this purpose is now rare. Prosthetic grafts are more widely used, amounting to $5-10 \%$ of patients in most series 
(Brom, 1965 ; Report of the Section on Cardiovascular Surgery, 1957; Schuster and Gross, 1962).

It is exceedingly difficult to extract from published reports the short- or long-term results using prosthetic grafts. Our own experience has been disappointing, with only two satisfactory results in five cases.

MORTALITY AND COMPLICATIONS Operative mortality figures depend on the age of the subject and the presence or absence of associated anomalies (Schumacker et al., 1968; Tawes, Aberdeen, Waterston, and Bonham Carter, 1969). While in young adults with pure coarctation most centres report mortality figures up to 5 or $6 \%$ (Braimbridge and Yen, 1965 ; Brom, 1965; Karnell, 1968 ; Morris et al., 1960 ; Schuster and Gross, 1962), rates of 1 and $2 \%$ have been reported (Gross, 1953 ; Sellors and Hobsley, 1963). These figures rise sharply in infancy and in the elderly age groups. In infancy the mortality is usually over 20\% (Brom, 1965 ; Hallman, Yashar, Bloodwell, and Cooley, 1967 ; Shumacker et al., 1968), while at the other end of the age scale, Report of the Section on Cardiovascular Surgery (1957) finds a mortality of $11.3 \%$ in patients over 30 years, and Braimbridge and Yen (1965) $13 \%$ in patients over 40 years. In this series one death occurred in infancy, four in men over 30, with no deaths in the intermediate age groups.

The incidence of operative death in this series of patients was strongly associated with electrocardiographic evidence of left ventricular ischaemia, which was present before operation in all four adults who died. While this represents a mortality of $42 \%$ of adult males over 30 years who had left ventricular ischaemia, such a strong association may be misleading, as only two were directly related to the ischaemic factor. Nevertheless, these patients incur a significant operative risk and a widely based review of the risks of operation, or medical treatment alone, should enable the selection of these cases for surgery to proceed on a sound basis.

At least two of these deaths would not be expected to occur today. More satisfactory prosthetic materials would not normally permit prolonged bleeding through a preclotted graft. Tawes et al. (1969) report that respiratory failure was an important cause of death in infants in the past, but current methods in the management of respiratory failure would now be expected to prevent the death of the 6-week-old infant.

Late mortality after surgery does occur, although only a few authors refer to it. In a series similar to this, Braimbridge and Yen (1965) experienced a late mortality of $4 \%$, while Sellors and Hobsley (1963) report a late mortality of $2 \%$. Braimbridge and Yen (1965) also show that in patients over 40 the total mortality may rise to $19 \%$.

The post-operative complications of surgery for coarctation have been frankly discussed by Owens and Swan (1963), who reported a complication rate of $23 \%$. Our own rate of $14 \%$ represents 10 patients, of whom one has residual disability. This is the girl who developed paraplegia following replacement of the aorta with a Teflon prosthesis. In many large series this complication occurs in $1 \%$ of cases (Gross, 1953 ; Owens and Swan, 1963 ; Shumacker et al., 1968). It may develop early or late after surgery, and is generally due to a combination of poor collaterals, a long period of aortic occlusion and resection of a long segment of aorta, which may lead to early thrombosis or spasm of the anterior spinal arteries. When the onset is delayed and the cause presumed to be vasculitis, similar to mesenteric arteritis, recovery is likely (Rosenkrantz and Paton, 1967). If the risk can be foreseen, prevention may be possible using hypothermia, with or without left atrial-femoral bypass (Owens and Swan, 1963).

BLOOD PRESSURE The basic alteration in haemodynamics is to be understood in terms of obstruction to aortic flow, with proximal hypertension and potential distal ischaemia compensated for by the development of a collateral circulation. The cause of the proximal hypertension remains partly in dispute. There is conflicting evidence regarding a humoral agent arising from the kidney (Friedman, Selzer, and Rosenblum, 1941 ; Timmis and Gordon, 1964), but Taylor and Donald (1960) have demonstrated elevation of total peripheral resistance to levels comparable with what is found in essential hypertension. They found only a small fall in total peripheral resistance after operation, which partly accounts for the fact that the blood pressure does not return completely to normal after surgery.

Since variations of normal blood pressure in the population, according to age and sex, were documented by Pickering and his colleagues (Hamilton et al., 1954; Pickering, 1968), it is helpful when recording the blood pressure to allow for these factors. In the past, the effects of resection of coarctation on blood pressure have been recorded either as a mean fall in measured 
blood pressure (Karnell, 1968; Taylor and Donald, 1960 ; Cleland, Counihan, Goodwin, and Steiner, 1956) or as the percentage of individuals falling into arbitrary categories representing 'normal', 'acceptable', and 'high' blood pressures (Gross, 1953; Groves and Effler, 1960 ; Shumacker et al., 1968). Sellors and Hobsley (1963) were the first to use age and sex corrections. If published results are to be comparable, authors should use these corrections and publish both the mean fall in blood pressure score and the percentage of individuals whose score remains over an arbitrary figure, such as 50 , which is equivalent to a systolic pressure of $150 \mathrm{~mm}$. $\mathrm{Hg}$ in young adult males. Unless this is done, it is impossible to compare blood pressure in males and females, at all ages, over spans of 20 years, and in different papers.

PRE- AND EARLY POST-OPERATIVE PRESSURES The pattern of elevated blood pressure before operation in this series demonstrates, like Sellors and Hobsley (1963), a peak score at 25 to 30 years, but we did not show that above this age there is a further proportionate rise in blood pressure (Karnell, 1968). Males had much higher scores than females.

That the rate of fall of blood pressure immediately after operation is slow is well known (Shumacker et al., 1968). Recent papers have shown that, in addition to the persistence of high total peripheral resistance (Taylor and Donald, 1960), there is an increased secretion of catecholamines in the early post-operative period (Goodall and Sealy, 1969; O'Gorman, Wilson, and Castillo-Olivares, 1969). Although Sellors and Hobsley (1963) report that the blood pressure failed to fall immediately to satisfactory levels in only $2 \%$, Karnell (1968) reports that this was so in $25 \%$ of cases, while Rathi and Keith (1964) report that $43 \%$ of patients had blood pressures actually higher than before operation. In this series $38 \%$ of patients had scores over 50 at the time of discharge.

LATE POST-OPERATIVE BLOOD PRESSURES Sellors and Hobsley (1963) report their results in terms of mean corrected blood pressure, which is an alternative way of applying age and sex correction (Hamilton et al., 1954). After 5 to 10 years' follow-up there had been a fall to $70 \%$ of the pre-operative level. Using the same correction in our series, there is a fall to $65 \%$ after 5 to 17 years' follow-up. Their conclusion that the fall in blood pressure lasts at least 5 to 10 years may, therefore, be carried further with this evidence that it is maintained for up to 17 years. A satisfactory fall in blood pressure may be expected in all age groups and at all levels of pre-operative hypertension.

CHEST RADIOGRAPH The radiological abnormalities in coarctation are well known (Friedberg, 1966). Among 52 patients, Cleland et al. (1956) found rib-notching, left ventricular enlargement and abnormalities of the aortic knuckle, in that order, to be the most common findings. Our findings correspond precisely, and, like Cleland, we also found that enlarged left ventricles remain larger than normal after operation. As the preoperative and post-operative films were not comparable, it is not possible to say whether any reduction in size took place.

ELECTROCARDIOGRAM In series including all age groups, left ventricular hypertrophy and strain occur in 50 to $75 \%$ of cases, while in older age groups this figure rises to $90 \%$ (Braimbridge and Yen, 1965; Campbell and Baylis, 1956). Conversely, Karnell (1968) states that if left ventricular ischaemia occurs in patients under 30 years, one should look for associated aortic stenosis. In the total series, six patients under 30 years had electrocardiographic evidence of left ventricular ischaemia, but only one had aortic stenosis and one had aortic incompetence. However, there is post-mortem evidence that myocardial ischaemia may be present in the absence of the usual electrocardiographic abnormalities and may be an important cause of post-operative mortality in infants (Tawes et al., 1969).

Cleland and his colleagues (1956) reported that left ventricular hypertrophy did not return to normal after operation, but, like Schuster and Gross (1962), who reported that $69 \%$ returned to normal, we found that $79 \%$ showed improvement or return to normality after long periods of follow-up.

\section{CONCLUSIONS}

1. Simple resection and end-to-end anastomosis or aortoplasty were found to be satisfactory and safe procedures in the majority of patients.

2. The use of prostheses carried a high risk in our experience.

3. Carification is needed of the indications for surgery in men over $\mathbf{3 0}$ years who have left ventricular ischaemia.

4. A plea is made for the use of age and sex corrections when recording blood pressures. 
5. A satisfactory reduction in blood pressure has been demonstrated in all groups of patients following operation, and this has been maintained for up to 17 years.

I wish to thank Mr. J. A. W. Bingham, Mr. T. B. Smiley, Mr. H. M. Stevenson, and Dr. J. F. Pantridge for permission to report their patients and encouragement in carrying out this work. To Dr. E. McIlrath and Dr. G. C. Patterson, who helped with radiology and electrocardiography, to Mrs. C. Dawbarn, who prepared the figures, and to Miss M. Linforth, who typed the script, I wish to express my gratitude.

\section{REFERENCES}

Abbott, M. E. (1928). Coarctation of the aorta of the adult type II. A statistical study and historical retrospect of 200 recorded cases, with autopsy, of stenosis or obliteration of the descending arch in subjects above the age of two years. Amer. Heart J., 3, 392 .

Blalock, A., and Park, E. A. (1944). The surgical treatment of experimental coarctation (atresia) of the aorta. Ann. Surg., 119, 445.

Braimbridge, M. V. and Yen, A. (1965). Coarctation in the elderly. Circulation, 31, 209.

Brom, A. G. (1965). Narrowing of the aortic isthmus and enlargement of the mind. J. thorac. cardiovasc. Surg., 50, 166.

Bull, C., Hoeksema, T., Duckworth, J. A., and Mustard, W. T. (1963). An experimental study of the growth of arterial anastomoses. Canad. J. Surg., 6, 383.

Campbell, M., and Baylis, J. H. (1956). The course and prognosis of coarction of the aorta. Brit. Heart J., 18, 475 .

Cleland, W. P., Counihan, T. B., Goodwin, J. F., and Steiner, R. E. (1956). Coarction of the aorta. Brit. med. J., $2,379$.

Cooley, D. A., Debakey, M. E., and Morris, G.'C. (1957). Controlled extracorporeal circulation in surgical treatment of aortic aneurysm. Ann. Surg., 146, 473.

Crafoord, C., and Nylin, G. (1945). Congenital coarctation of the aorta and its surgical treatment. J. thorac. Surg. 14, 347.

Foster, J. H., Collins, H. A., Jacobs, J. K., and Scott, H. W., Jr (1965). Long term follow-up of homografts used in the treatment of coarctation of the aorta. J. cardiovasc. Surg., 6,111 .

Frederiksen, T., and Møller, A. G. (1964). Controlled hypotension in operation for coarctation of the aorta. Acta chir. scand.,
127,338 .

Friedberg, C. K. (1966). Diseases of the Heart, 3rd ed. Saunders, Philadelphia and London.

Friedman, M., Selzer, A., and Rosenblum, H. (1941). The renal blood flow in coarctation of the aorta. J. clin. Invest., 20, 107.

Goodall, McC., and Sealy, W. C. (1969). Increased sympathetic nerve activity following resection of coarctation of the thoracic aorta. Circulation, 39, 345.

Gross, R. E. (1953). Coarctation of the aosta. Circulation, 7, 757

- _ - and Hufnagel, C. A. (1945). Coarctation of the aorta; experimental studies regarding its surgical correction. New Engl. J. Med., 233, 287.
Groves, L. K., and Effler, D. B. (1960). Problems in the surgical management of coarctation of the aorta. J. thorac. cardiovasc. Surg., 39, 60.

Hallman, G. L., Yashar, J. J., Bloodwell, R. D., and Cooley, D. A. (1967). Surgical correction of coarctation of the aorta in the first year of life. Ann. thorac. Surg., 4, 106.

Hamilton, M., Pickering, G. W., Roberts, J. A. F., and Sowry, G. S. C. $\vec{\nabla}$ (1954). The aetiology of essential hypertension. 2. Scores for $Q$ arterial blood pressures adjusted for differences in age and sex. Clin. Sci., 13, 37.

Karnell, J. (1968). Coarctation of the aorta. Circulation, 38, Suppl. 5, p. 35 .

Marshall, R. J., and Pantridge, J. F. (1956). Coarctation of the aorta. Irish J. med. Sci., no. 371, p. 491.

Morris, G. C., Jr., Cooley, D. A., De Bakey, M. E. and Crawford, E. S. (1960). Coatctation of the aorta with particular emphasis upon improved techniques of surgical repair. J. thorac. cardio- $\vec{x}$ vasc. Surg., 40, 705.

Mortensen, J. D., Cutler, P. R., Rumel, W. R., and Veasy, L. G. 心 (1959). Management of coarctation of the aorta in infancy. $\omega$
J. thorac. cardiovasc. Surg., 37, 502.

Neville, W. E., Cox, W. D., Leininger, B., and Pifarré, R. (1968). W Resection of the descending thoracic aorta with femoral vein to femoral artery oxygenation perfusion. J. thorac. cardiovasc. to femoral artery oxygenation perfusion. J. thorac. cardiovasc.
Surg., 56, 39 . Surg., 56, 39.

O'Gorman, L. P., Wilson, A. M., and Castillo-Olivares, J. (1969). Abnormal levels of catecholamine metabolites in a resected coarctation of the aorta. Brit. J. Surg., 56, 183.

Owens, J. C., and Swan, H. (1963). Complications in the repair of coarctation of the aorta. J. cardiovasc. Surg., $4,816$.

Pelletier, C., Davignon, A., F.-Ethier, M., and Stanley, P. (1969). $\vec{c}$ Coarctation of the acrta in infancy. J. thorac. cardiovasc. Surg., 57,171 .

Pickering, G. (1968). High Blood Pressure, 2nd ed. Churchill, London.

Rathi, L., and Keith, J. D. (1964). Post-operative blood pressures in coarctation of the aorta. Brit. Heart J., 26, 671. Reifenstein, G. H., Levine, S. A., and Gross, R. E. (1947). Coarcta-
tion of the aorta. Amer. Heart J., 33, 146.

Report of the Section on Cardiovascular Surgery (1957). Surgical treatment of coarctation of the aorta. Dis. Chest, 31, 468.

Rosenkrantz, J. G., and Paton, B. C. (1967). Results of cardiac surgery in infants and children. In Cardiac Surgery, ed. J. C. $\overline{\bar{O}}$ Norman, p. 267. Butterworths, London.

Schuster, S. R., and Gross, R. E. (1962). Surgery for coarctation of the aorta. A review of 500 cases. J. thorac. cardiovasc. Surg., 43, 54.

Sellors, T. H., and Hobsley, M. (1963). Coarctation of the aorta. Effect of operation on blood pressure. Lancet, 1, 1387.

Shumacker, H. B., Jr., King, H., Nahrwold, D. L., and Waldhausen, J. A. (1968). Coarctation of the aorta. Current Problems in Surgery. February, 1968. Year Book Medical Publishers, Chicago.

Tawes, R. L., Jr., Aberdeen, E., Waterston, D. J., and Bonham Carter, R. E. (1969). Coarctation of the aorta in infants and children. A review of 333 operative cases, including 179 infants. Circulation, 39, Suppl. 1, p. 173.

Taylor, S. H., and Donald, K. W. (1960). Circulatory studies at rest and during exercise in coarctation of the aorta before and after operation. Brit. Heart J., 22, 117.

Timmis, G. C., and Gordon, S. (1964). A renal factor in hypertension due to coarctation of the aorta. New Engl. J. Med., 270, 814.

Vossschulte, K. (1961). Surgical correction of coarctation of the aorta by an 'isthmusplastic' operation. Thorax, 16, 338. 